\title{
COMIMUNICATION
}

Cite this: Analyst, 2013, 138, 4280

Received 11th April 2013

Accepted 10th May 2013

DOI: 10.1039/c3an00725a

\section{Fluorescent sensing of mercury(II) based on formation of catalytic gold nanoparticles $\uparrow$}

\author{
Lixia Yan, ${ }^{a}$ Zhaopeng Chen, ${ }^{\text {b }}$ Zhiyang Zhang, ${ }^{\text {bc }}$ Chengli Qu, ${ }^{\mathrm{b}}$ Lingxin Chen ${ }^{\mathrm{b}}$ \\ and Dazhong Shen ${ }^{\star a}$
}

www.rsc.org/analyst

A fluorescence assay for the highly sensitive and selective detection of $\mathrm{Hg}^{2+}$ using a gold nanoparticle (AuNP)-based probe was proposed. The assay was based on the formation of $\mathrm{Hg}-\mathrm{Au}$ alloys, which accelerated the oxidization of o-phenylenediamine by dissolved oxygen to produce 2,3-diaminophenazine, a fluorescent product.

As a bioaccumulative and highly toxic heavy metal, mercury causes serious human health problems even at very low concentration. ${ }^{1}$ The solvated divalent mercuric ion $\left(\mathrm{Hg}^{2+}\right)$ is one of the most common and stable forms of mercury pollution due to its high water solubility. The development of highly sensitive and selective methods for the determination of $\mathrm{Hg}^{2+}$ is therefore of significant importance for the environment and human health and is the subject of current analytical chemical research. To realize this goal, besides atomic absorption/emission spectroscopy, ${ }^{2}$ selective cold vapor atomic fluorescence spectrometry, ${ }^{3}$ and inductively coupled plasma mass spectrometry (ICP-MS), ${ }^{4}$ a number of highly sensitive and selective $\mathrm{Hg}^{2+}$ sensors using organic chromophores, ${ }^{5}$ conjugated polymers,${ }^{6}$ proteins, ${ }^{7}$ oligonucleotides,${ }^{8}$ DNAzymes, ${ }^{9}$ antibodies, ${ }^{10}$ quantum $\operatorname{dots}^{\mathbf{1 1}}$ and metal nanoparticles ${ }^{\mathbf{1 2}}$ have also been developed for fluorescent, colorimetric, and electrochemical detection of $\mathrm{Hg}^{2+}$ in aqueous solution. Although these methods have achieved high sensitivity toward the determination of $\mathrm{Hg}^{2+}$, each of these approaches has its own drawbacks that limit practical use, such as the poor aqueous solubility of some

${ }^{a}$ The Key Lab in Molecular and Nano-materials Probes of the Ministry of Education of China, College of Chemistry, Chemical Engineering and Materials Science, Shandong Normal University, Jinan 250014, P. R. China.E-mail: dzshen@sdnu.edu.cn; Fax: +86 0531 82615258; Tel: +86053186180740

${ }^{b}$ Key Laboratory of Coastal Zone Environmental Processes, Yantai Institute of Coastal Zone Research (YIC), Chinese Academy of Sciences (CAS), Shandong Provincial Key Laboratory of Coastal Zone Environmental Processes, YICCAS, Yantai 264003, P. R. China. E-mail: zhpchen@yic.ac.cn; Fax: +86 0535 2109133; Tel: +86 05352109133 ${ }^{c}$ Graduate University of Chinese Academy of Sciences, Beijing 100049, P. R. China

$\uparrow$ Electronic supplementary information (ESI) available: Experimental details and Fig. S1-S4. See DOI: 10.1039/c3an00725a fluorophores, cross-sensitivity toward other metal ions, and the sophisticated synthesis of probe materials. Therefore, it is desirable to develop new methods to overcome these limitations.

Catalytic kinetic methods for photometric or fluorometric determination of heavy metal ions have been proved to be more sensitive compared with many other methods. ${ }^{13}$ Unfortunately, there is almost no appropriate catalytic reaction that could be applied to detect $\mathrm{Hg}^{2+}$ except for catalytic ligand substitution reaction, ${ }^{\mathbf{1 4}}$ which suffers from high detection limit. To overcome this drawback, recently, Long et al. ${ }^{15}$ and Wang et al. ${ }^{16}$ described a colorimetric and a fluorescent probe for determination of $\mathrm{Hg}^{2+}$, respectively. The detection limit was remarkably reduced to 0.3 and $4.0 \mathrm{nM}$, respectively. The strategy is based on the formation of $\mathrm{Hg}-\mathrm{Au}$ alloys, a peroxidase-like nanomaterial, which catalyzed the reaction between substrate and $\mathrm{H}_{2} \mathrm{O}_{2}$.

In this study, we found that the formed $\mathrm{Hg}-\mathrm{Au}$ alloys could also accelerate the oxidization of $o$-phenylenediamine by dissolved oxygen to produce a fluorescent product. We try to use this phenomenon to develop a fluorescent method for sensing of $\mathrm{Hg}^{2+}$. Compared with Huang's and Chang's work, the method avoided the addition of extra oxidant, making the sensing system simpler.

Scheme 1 illustrates the sensing mechanism. In the absence of polyethylene glycol (PEG) stabilized AuNPs, the oxidization of

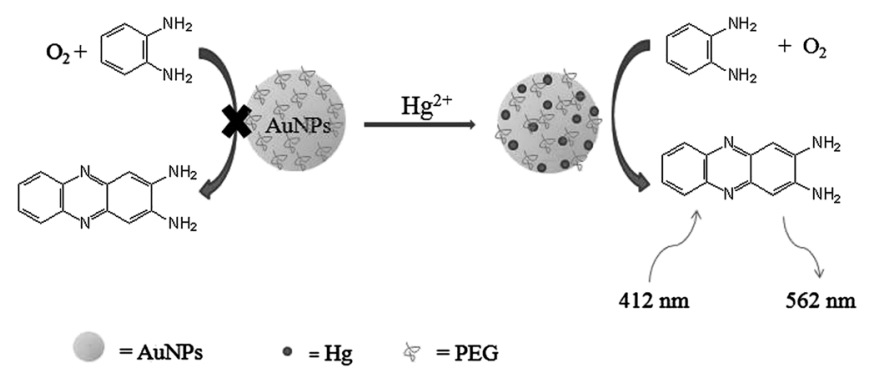

Scheme 1 Schematic illustration for the fluorescent sensing of mercury(॥) using AuNPs. 
$o$-phenylenediamine by dissolved oxygen is slow. The addition of $\mathrm{Hg}^{2+}$ to the solution resulted in the oxidization of citrate by $\mathrm{Hg}^{2+}$ and the formation of $\mathrm{Hg}-\mathrm{Au}$ alloys on AuNP surfaces (see evidence for formation of gold amalgam in the ESI $\dagger),{ }^{15}$ which accelerated the oxidation of $o$-phenylenediamine by dissolved oxygen to produce a fluorescent product, 2,3-diaminophenazine.

The absorption spectra of AuNPs $\left(8.4 \times 10^{-12} \mathrm{M}\right)$ in BR buffer in the absence and presence of $1.0^{-6} \mathrm{M} \mathrm{Hg}^{2+}$ ions are shown in Fig. 1. Compared with the absorption spectrum obtained in the presence of $\mathrm{Hg}^{2+}$ (curve b), the absorption spectrum obtained in the absence of $\mathrm{Hg}^{2+}$ (curve a) red-shifted slightly and seemed broader, revealing that the AuNPs aggregated slightly. The result is also consistent with what was reported by Long et al. ${ }^{15}$ At $\mathrm{pH} 5.65$, some of the acetate and citrate ions absorbed on AuNP surfaces were neutralized by the $\mathrm{H}^{+}$, leading to AuNPs aggregated slightly due to the decrease of the net charge density on the AuNP surfaces. The formation of the submonolayer of $\mathrm{Hg}$ on AuNP surfaces increased the adsorption of acetate and/or citrate anions on AuNPs, promoting the stability of AuNPs. ${ }^{16}$ From these results, we can also conclude that the AuNPs would aggregate to a certain degree if the concentration of $\mathrm{Hg}^{2+}$ is much less than $1.0 \times 10^{-6}$ M. Curves c and d show the absorption spectra of PEG stabilized AuNPs in BR buffer solution in the absence and presence of $1.0 \times 10^{-6} \mathrm{M} \mathrm{Hg}^{2+}$, respectively. The difference between these two curves is negligible. This result indicated that PEG stabilized AuNPs were more stable than citrate-capped AuNPs. It should be noted here that the addition of PEG to the sensing system promoted the sensing reproducibility. The relative standard deviation (RSD) for sensing of $5.0 \times 10^{-8} \mathrm{M} \mathrm{Hg}^{2+}$ is $4.7 \%$, which is much less than that obtained in the absence of PEG (15.6\%). The decrease of RSD maybe resulted from the low aggregation degree of AuNPs.

To confirm that the redox reaction between dissolved oxygen and $o$-phenylenediamine was accelerated by the formed $\mathrm{Hg}-\mathrm{Au}$ alloys, the fluorescence spectra were recorded separately in the presence of $\mathrm{Hg}^{2+}$, PEG-AuNPs and combination of $\mathrm{Hg}^{2+}$ and PEG-AuNPs. As shown in Fig. 2, the fluorescence intensity in the

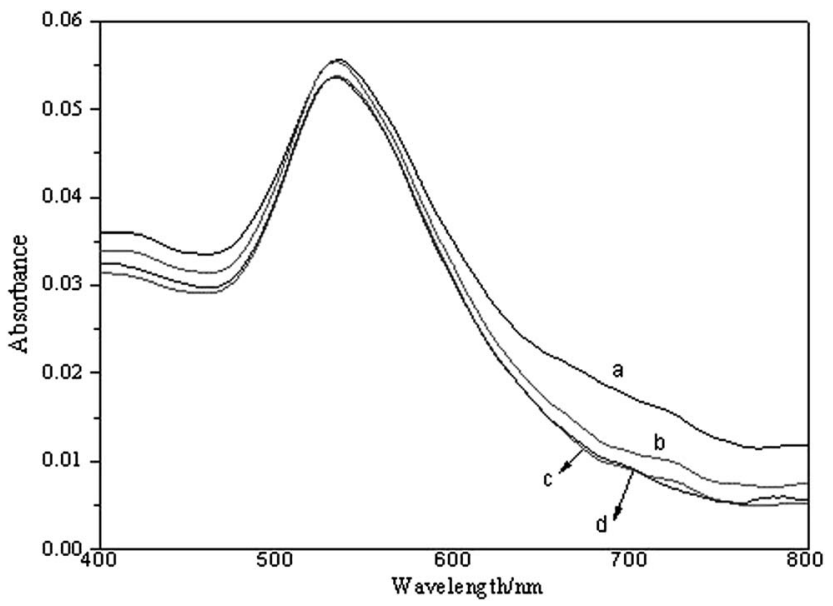

Fig. 1 Absorption spectra of AuNPs in the absence ( $a$ and $b$ ) and presence ( $c$ and d) of PEG before ( $a$ and $c$ ) and after ( $b$ and $d$ ) the addition of $1.0^{-6} \mathrm{M} \mathrm{Hg}^{2+}$.

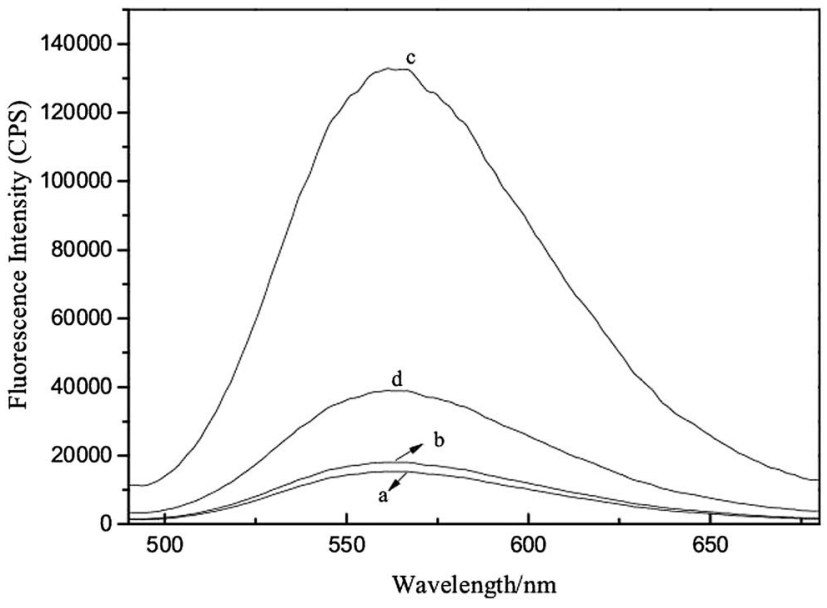

Fig. 2 Fluorescence emission graph of o-phenylenediamine after incubation with different reagents.

presence of $\mathrm{Hg}^{2+}$ is very low, indicating almost no obvious reaction between $o$-phenylenediamine and dissolved oxygen occurred (curve a). The reaction between $o$-phenylenediamine and dissolved oxygen can be catalysed by PEG-AuNPs slightly (curve b). The addition of $50 \mathrm{nM} \mathrm{Hg}^{2+}$ led to a remarkable increase in fluorescence intensity with the presence of PEG-AuNPs (curve c), indicating that the redox reaction was accelerated by the co-effect of PEG-AuNPs and $\mathrm{Hg}^{2+}$. Curve $\mathrm{d}$ demonstrates that the dissolved oxygen was used as an oxidant. The removal of oxygen by pumping nitrogen into the solution resulted in a dramatic decrease in fluorescence intensity.

It was reported that $\mathrm{Cu}^{2+}$ and $\mathrm{Ag}^{+}$could oxidize $o$-phenylenediamine to 2,3-diaminophenazine. ${ }^{17}$ The standard potentials of $\mathrm{Cu}^{2+} / \mathrm{Cu}$ and $\mathrm{Ag}^{+} / \mathrm{Ag}$ are 0.337 and $0.799 \mathrm{~V}$ vs. standard hydrogen electrode (NHE), respectively. We can conclude that the standard potential of 2,3-diaminophenazine/o-phenylenediamine is less than $0.337 \mathrm{~V}$ ( $v s$. NHE). The practical potential of $\mathrm{O}_{2} / \mathrm{H}_{2} \mathrm{O}$ at pH 5.65 is about $0.9 \mathrm{~V}$ ( $v s$. NHE) calculated according to the Nernst equation. Thermodynamically, $o$-phenylenediamine can be oxidized by dissolved oxygen to produce 2,3-diaminophenazine. The oxidation of $o$-phenylenediamine in the absence of $\mathrm{Hg}-\mathrm{Au}$ nanoparticles is very slow due to the high activation energy. The reaction rate between $o$-phenylenediamine and oxygen was accelerated by gold amalgam nanoparticles which may be due to the decrease of the reaction activation energy or the formation of a galvanic cell in which the dissolved oxygen was reduced and $o$-phenylenediamine was oxidized electrochemically.

To estimate the selectivity of such catalytic gold nanoparticles toward $\mathrm{Hg}^{2+}$, 15 other metal ions were also investigated under optimal conditions ( $\mathrm{pH} 5.65$, AuNP volume $15 \mu \mathrm{L}$, $o$-phenylenediamine concentration $2.1 \mathrm{mM}$, incubation time 25 min, see Fig. S2-S5 in the ESI $\dagger$ ), as shown in Fig. 3. Among the tested metal ions, $5 \times 10^{-8} \mathrm{M} \mathrm{Hg}^{2+}$ produced a very strong fluorescence signal. While 20-fold of $\mathrm{Ca}^{2+}, \mathrm{Mg}^{2+}, \mathrm{Zn}^{2+}, \mathrm{Cr}^{3+}$, $\mathrm{Pb}^{2+}, \mathrm{Cr}(\mathrm{vI}), \mathrm{Mn}^{2+}, \mathrm{Cd}^{2+}, \mathrm{Fe}^{3+}, \mathrm{Al}^{3+}, \mathrm{Ni}^{2+}, 10$-fold of $\mathrm{Fe}^{2+}, \mathrm{Co}^{2+}$, 5 -fold of $\mathrm{Cu}^{2+}$ and the same concentration of $\mathrm{Ag}^{+}$caused almost no fluorescence signal, indicating that the sensor displayed 


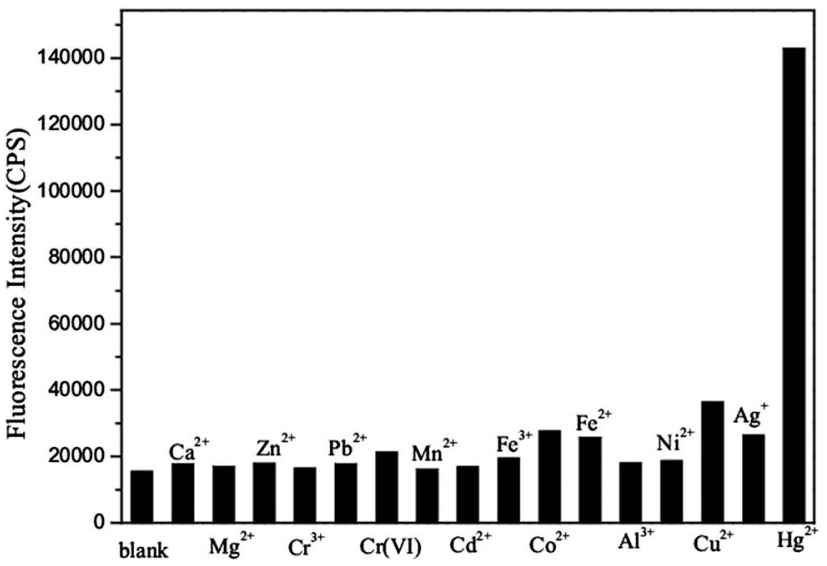

Fig. 3 Fluorescence responses to common metal ions at $1.0 \mu \mathrm{M}$ (besides $\mathrm{Hg}^{2+}$ $50 \mathrm{nM}, \mathrm{Cu}^{2+} 250 \mathrm{nM}$, and $\mathrm{Ag}^{+} 50 \mathrm{nM}$ ) under optimal conditions.

excellent selectivity toward $\mathrm{Hg}^{2+}$. The higher concentration of $\mathrm{Cu}^{2+}$ and $\mathrm{Ag}^{+}$caused a relatively strong fluorescence response because $o$-phenylenediamine could be oxidized by $\mathrm{Cu}^{2+}$ and $\mathrm{Ag}^{+}$ in the presence of nanoparticles. ${ }^{17}$

Fig. 4 depicts the fluorescence analysis of different concentrations of $\mathrm{Hg}^{2+}$ using the proposed method under optimal conditions. The fluorescence intensity at $562 \mathrm{~nm}$ was enhanced as the $\mathrm{Hg}^{2+}$ concentration increased. This indicated that the oxidation of $o$-phenylenediamine was accelerated with the increase of $\mathrm{Hg}^{2+}$ concentration. The inset in Fig. 4 shows the relationship between the fluorescence intensity at $562 \mathrm{~nm}$ and the $\mathrm{Hg}^{2+}$ concentration. A linear detection range from 5.0 to $100 \mathrm{nM}$ was achieved (linear equation: $F=2886.7 C-349$ ). The detection limit was calculated to be $2.24 \mathrm{nM}$ according to the $3 \sigma$-rule (where $\sigma$ is the standard deviation of blank solution and $n=10)$.

To test the applicability of the probe for $\mathrm{Hg}^{2+}$ detection in real samples, the probe was applied to the detection of $\mathrm{Hg}^{2+}$ in drinking water. $\mathrm{No}_{\mathrm{Hg}^{2+}}$ was detected in such sample, which

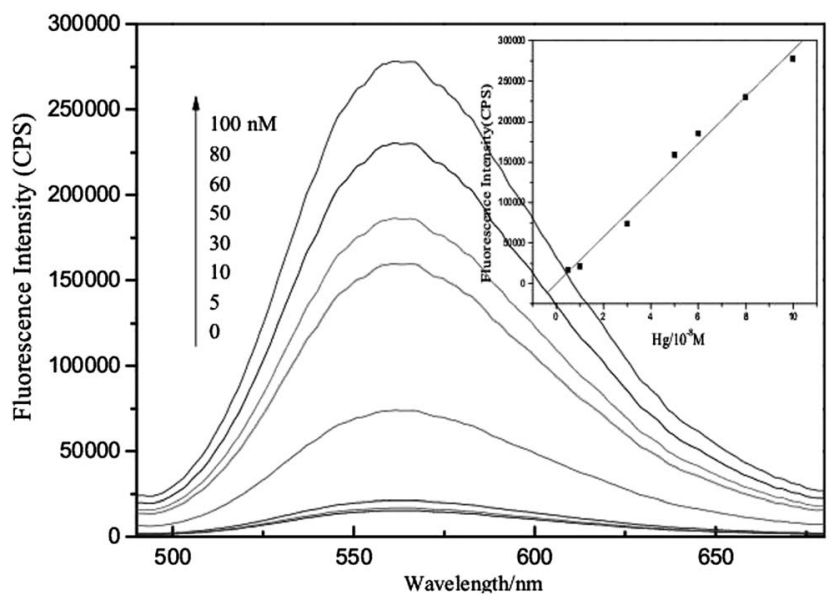

Fig. 4 Fluorescence spectra for analysing different concentrations of $\mathrm{Hg}^{2+}$ (from bottom to top): $0,5.0,10,30,50,60,80$ and $100 \mathrm{nM}$. The inset shows the dependence of fluorescence intensity at $562 \mathrm{~nm}$ on the concentration of $\mathrm{Hg}^{2+}$.
Table 1 The recovery of spiked $\mathrm{Hg}^{2+}$ in local drinking water. The standard deviation of each sample was obtained by three measurements

\begin{tabular}{lccr}
\hline Sample & Added/nM & Found/nM & Recovery (\%) \\
\hline Sample 1 & 20.0 & $17.9 \pm 0.8$ & $89.5 \pm 4.1$ \\
Sample 2 & 40.0 & $37.1 \pm 1.1$ & $92.8 \pm 2.7$ \\
Sample 3 & 60.0 & $63.2 \pm 0.4$ & $105.3 \pm 0.7$ \\
Sample 4 & 80.0 & $85.2 \pm 0.3$ & $106.5 \pm 3.3$ \\
Sample 5 & 100.0 & $97.2 \pm 1.6$ & $97.2 \pm 1.6$ \\
\hline
\end{tabular}

was later verified by ICP-MS. The method was alternatively tested by standard addition and the recovery of spiked $\mathrm{Hg}^{2+}$ ranged from 89.5 to 106.5 (Table 1 ). The probe proved to be a practical and sensitive method for the fast inspection of $\mathrm{Hg}^{2+}$.

In conclusion, we have proposed a novel fluorescent method for sensing of $\mathrm{Hg}^{2+}$ based on formation of catalytic gold nanoparticles automatically. The formed gold amalgam nanoparticles exhibited excellent catalytic property, accelerating the oxidation of $o$-phenylenediamine by dissolved oxygen to produce a fluorescent product. Compared with other sensors for detection of $\mathrm{Hg}^{2+}$, the novel probe possesses several attractive features: (i) simplicity, because sensing only needs mixing of $o$-phenylenediamine, AuNPs and samples before fluorescence detection without addition of extra oxidant; ${ }^{15,16}$ (ii) low cost, because expensive reagents, such as DNAzyme, ${ }^{9}$ DNA, ${ }^{8}$ and other high selective recognition molecules, ${ }^{5,6 \boldsymbol{6}}$ are not needed; (iii) sensitivity, because the detection limit was reduced to $2.0 \mathrm{nM}$. In addition, the probe was utilized for inspection of $\mathrm{Hg}^{2+}$ in drinking water and the result indicated that the sensor could be applied to estimate $\mathrm{Hg}^{2+}$ contaminant in real samples.

The research was financially supported by the Department of Science and Technology of Shandong Province (BS2009DX006, 2008GG20005005), NSFC (no. 21275158, 21175084, 21275091), CAS (KZCX2-YW-JS208) and the 100 Talents Program of the CAS.

\section{Notes and references}

1 (a) W. Zheng, M. Aschner and J. F. Ghersi-Egea, Toxicol. Appl. Pharmacol., 2003, 192, 1; (b) D. P. Wojcik, M. E. Godfrey, D. Christie and B. E. Haley, Neuroendocrinol. Lett., 2006, 27, 415; (c) S. Koenig, M. Sole, C. Fernandez-Gomez and S. Diez, Sci. Total Environ., 2013, 442, 329.

2 (a) M. Thompson and B. J. Coles, Analyst, 1984, 109, 529; (b) H. Erxleben and J. Ruzicka, Anal. Chem., 2005, 77, 5124.

3 (a) Y. W. Chen, J. Tong, A. D'Ulivo and N. Belzile, Analyst, 2002, 127, 1541; (b) Y. Li, Y. Xu, Y. Huang, Y. Dai, Q. Hu and G. Yang, Asian J. Chem., 2009, 21, 2893.

4 (a) M. J. Powell, E. S. K. Quan, D. W. Boomer and D. R. Wiederin, Anal. Chem., 1992, 64, 2253; (b) S. J. Christopher, S. E. Long, M. S. Rearick and J. D. Fassett, Anal. Chem., 2001, 73, 2190.

5 (a) W. Huang, C. Song, C. He, G. Lv, X. Hu, X. Zhu and C. Duan, Inorg. Chem., 2009, 48, 5061; (b) H. Y. Lee, J. Jo, H. Park and D. Lee, Chem. Commun., 2011, 47, 5515.

6 (a) N. Y. Kwon, D. Kim, J. H. Son, G. S. Jang, J. H. Lee and T. S. Lee, Macromol. Rapid Commun., 2011, 32, 1061; (b) 
E. S. Childress, C. A. Roberts, D. Y. Sherwood, C. L. M. LeGuyader and E. J. Harbron, Anal. Chem., 2012, 84, 1235; (c) W. Huang and W. Wu, J. Appl. Polym. Sci., 2012, 124, 2055.

7 (a) L.-J. Ma, Y. Li, L. Li, J. Sun, C. Tian and Y. Wu, Chem. Commun., 2008, 6345; (b) Z. Gu, M. Zhao, Y. Sheng, L. A. Bentolila and Y. Tang, Anal. Chem., 2011, 83, 2324.

8 (a) C.-K. Chiang, C.-C. Huang, C.-W. Liu and H.-T. Chang, Anal. Chem., 2008, 80, 3716; (b) S.-J. Liu, H.-G. Nie, J.-H. Jiang, G.-L. Shen and R.-Q. Yu, Anal. Chem., 2009, 81, 5724; (c) Z. Zhu, Y. Su, J. Li, D. Li, J. Zhang, S. Song, Y. Zhao, G. Li and C. Fan, Anal. Chem., 2009, 81, 7660; (d) F. Ma, Y. Zhang, H. Qi, Q. Gao, C. Zhang and W. Miao, Biosens. Bioelectron., 2012, 32, 37.

9 (a) J. Liu and Y. Lu, Angew. Chem., Int. Ed., 2007, 46, 7587; (b) T. Li, S. Dong and E. Wang, Anal. Chem., 2009, 81, 2144; (c) T. Li, B. Li, E. Wang and S. Dong, Chem. Commun., 2009, 3551; (d) D. Zhang, M. Deng, L. Xu, Y. Zhou, J. Yuwen and X. Zhou, Chem.-Eur. J., 2009, 15, 8117.

10 (a) C. K. Prudente, R. S. Sirios and S. Cote, Anal. Biochem., 2010, 404, 179; (b) Y. Date, A. Aota, S. Terakado, K. Sasaki,
N. Matsumoto, Y. Watanabe, T. Matsue and N. Ohmura, Anal. Chem., 2013, 85, 434.

11 (a) M. Li, Q. Wang, X. Shi, L. A. Hornak and N. Wu, Anal. Chem., 2011, 83, 7061; (b) T. Li, Y. Zhou, J. Sun, D. Tang, S. Guo and X. Ding, Microchim. Acta, 2011, 175, 113.

12 (a) C.-Y. Lin, C.-J. Yu, Y.-H. Lin and W.-L. Tseng, Anal. Chem., 2010, 82, 6830; (b) D. Liu, W. Qu, W. Chen, W. Zhang, Z. Wang and X. Jiang, Anal. Chem., 2010, 82, 9606; (c) Y. Zhang, Q. Yuan, T. Chen, X. Zhang, Y. Chen and W. Tan, Anal. Chem., 2012, 84, 1956.

13 Z. Chen, N. Zhang, L. Zhuo and B. Tang, Microchim. Acta, 2009, 164, 311.

14 (a) M. Tabata, S. Funahash and M. Tanaka, Anal. Chim. Acta, 1972, 62, 289; (b) R. M. Naik and J. Sarkar, Indian J. Chem. Technol., 2005, 12, 563; (c) R. M. Naik, A. Agarwal and S. Prasad, Spectrochim. Acta, Part A, 2009, 74, 887.

15 Y. J. Long, Y. F. Li, Y. Liu, J. J. Zheng, J. Tang and C. Z. Huang, Chem. Commun., 2011, 47, 11939.

16 C.-I. Wang, C.-C. Huang, Y.-W. Lin, W.-T. Chen and H.-T. Chang, Anal. Chim. Acta, 2012, 745, 124.

17 X. Yang and E. Wang, Anal. Chem., 2011, 83, 5005. 